\title{
Paz en Colombia: perspectivas, desafíos, opciones
}

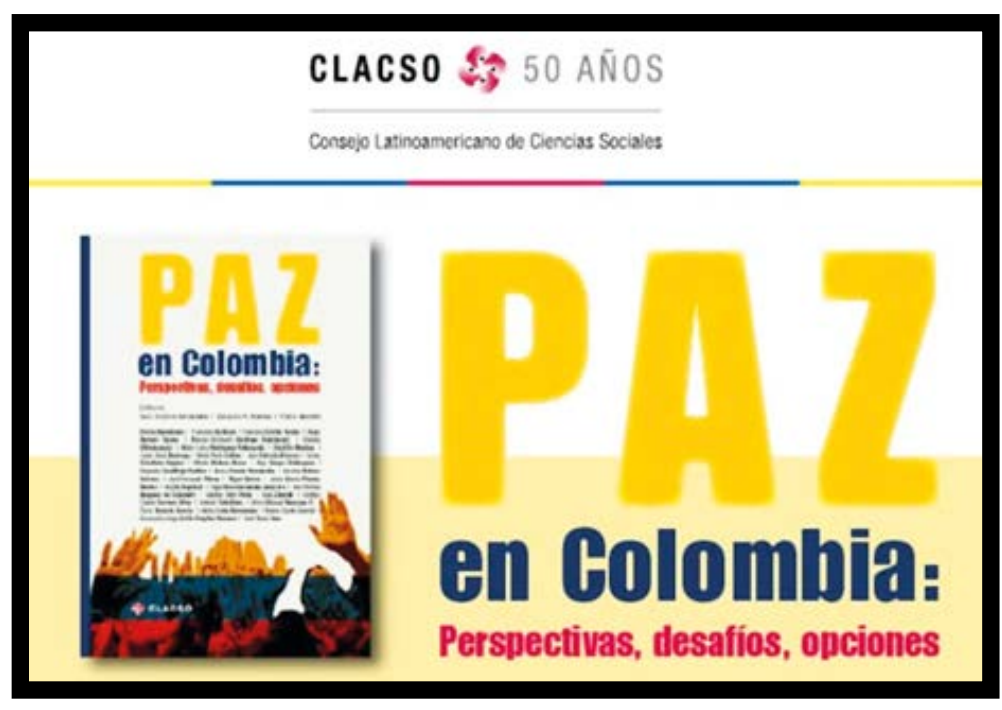

Eduardo Rueda, Sara Victoria Alvarado y Pablo Gentili (editores). 2016. Paz en Colombia: Perspectivas, desafíos, opciones. Buenos Aires: CLACSO, Libro digital PDF.

\section{Un aporte a la lucha por la paz en Colombia}

El acuerdo de paz entre el gobierno colombiano y las FARC constituye un hecho de inmensa relevancia en la historia democrática de América Latina. Marca el fin del conflicto armado y el inicio de un complejo desafío que significa el proceso de construcción colectiva de las condiciones que harán posible edificar un futuro mejor, más justo, democrático y libre para millones de colombianos y colombianas que han sufrido más de medio siglo de violencia, muerte y dolor.

Este libro pretende ser un aporte para analizar las diversas dimensiones sociales, políticas, económicas, culturales, educativas y éticas de los retos que precedieron al acuerdo de paz y que se desplegarán a partir de ahora. Se publica a pocos días del plebiscito del 2 de octubre de 2016, en el que la sociedad colombiana tendrá en sus manos la posibilidad de refrendar este importantísimo acuerdo, abriendo y multiplicando los desafíos y oportunidades que nos permitieron llegar hasta aquí. La lectura de cada una de las contribuciones de este volumen permite no sólo entender que es urgente y necesario votar por el Sí a los acuerdos de paz, sino también asumir la inmensa complejidad de una coyuntura que necesitará de muchísima imaginación, compromiso y participación democrática. La paz es siempre una construcción colectiva que nace de un consenso, de un acuerdo fundacional, pero que se reafirma día a día en acciones y responsabilidades compartidas que deben tornarla una realidad impostergable, concreta y real. La paz no puede ser sólo una promesa, sino la plataforma desde la cual construir un futuro de justicia, libertad y dignidad para todos. Por eso, este libro aspira a convertirse en una herramienta de trabajo, en una contribución analítica y en un aporte más a las luchas y a los desafíos que enfrentaremos los defensores, activistas y militantes de la paz en Colombia. CLACSO nació en Bogotá casi al mismo tiempo en que la guerra comenzaba a arrasar el país. Fue en 1967, en una histórica asamblea que reunió 
algunos de los mejores y más comprometidos intelectuales latinoamericanos y caribeños, en la Universidad Nacional de un país que, por aquel entonces, siquiera podía imaginar que se transformaría en el escenario de un horror que produjo más de 5 millones de víctimas, $220 \mathrm{mil}$ muertos y decenas de miles de desplazados, desaparecidos y secuestrados.

Desde aquel momento, y durante toda la guerra, CLACSO contribuyó activamente a la construcción de la paz en Colombia. Lo hicimos a través de nuestros grupos de trabajo, de centenas de investigaciones, de debates, libros, revistas y producciones académicas. Además, sumándonos a los procesos de movilización ciudadana que permitieron finalmente la firma de este importantísimo acuerdo de paz. En noviembre de 2015, CLACSO promovió en Medellín su gran conferencia internacional y su XXV Asamblea General, quizás el acto político académico más multitudinario a favor de la paz que se haya realizado en el país. Más de 30 mil inscriptos, $70 \%$ de ellos con menos de 30 años, pusieron en evidencia la enorme vitalidad y compromiso de una juventud colombiana que nunca se conformó con un presente de violencia e injusticia, con un futuro de barbarie y vergüenza. La Conferencia de Medellín, como será recordada, marcó un momento histórico no sólo mostrando la inmensa capacidad analítica y reflexiva sobre el presente, el pasado y el futuro de Colombia, sino también la convicción de que las ciencias sociales y las humanidades quizás no cambien por si solas la realidad, pero que la realidad, sin ellas, jamás cambiará de forma democrática; que las luchas por la emancipación humana, sin ellas, jamás podrán vencer y volverse una oportunidad efectiva $y$ concreta para los millones de seres humanos que, dentro y fuera de Colombia, no pretenden otra cosa que vivir con dignidad y tener sus derechos fundamentales respetados, afirmados y garantizados.

Paz en Colombia se organiza en cinco secciones. En la primera, “La paz en Colombia: visiones", se integran contribuciones diversas sobre el sentido de la paz, sus vínculos con el desarrollo, la justicia, la memoria, la cultura política y la civilidad, haciendo muchas de ellas hincapié en el significado que el proceso de paz $y$ los acuerdos logrados tienen para el presente y el futuro del país.

En la segunda parte, "El tránsito hacia el acuerdo final", se recogen artículos que elaboran retrospectivas críticas, en diversas escalas temporales, sobre el proceso de paz mismo, considerado globalmente, y sobre puntos específicos de la agenda de La Habana. El examen histórico-crítico revela reconfiguraciones de expectativas, discursos y estrategias en las que palpitan transiciones imaginarias, políticas y sociales del país en su conjunto.

La tercera sección, "El plebiscito por la paz: perspectivas", reúne contribuciones que sistematizan y proponen diversos conjuntos de argumentos para que los colombianos refrenden el Acuerdo Final entre el gobierno y las FARC en La Habana. Los análisis develan el sentido de las movilizaciones ciudadanas, exploran el carácter moral del plebiscito, exponen los argumentos que despejan los temores de quienes se le oponen y las dudas de los aún indecisos, y muestran el valor que el proceso mismo que precede al plebiscito tiene para el aprendizaje democrático.

En la cuarta sección, "La paz para el ambiente y la vida", se integran puntos de vista diversos sobre las importantes y positivas consecuencias que tendría la paz para el medio ambiente, y explora el sentido y alcance que se descubre en la paz cuando se muestra su conexión interna con el mandato ético-político de cuidar el ambiente y la vida.

Es desde este mandato que urgen respuestas frente a la minería intensiva y su efecto devastador sobre el ambiente. En este mismo marco de compromiso con la paz, se revela la importancia de nuevas lógicas, incluyentes y dignificantes, para habitar la ciudad.

En la quinta sección, "Las tareas de la paz", se recogen puntos de vista sobre las cuestiones cruciales que se siguen luego del Sí en el plebiscito por la paz: la inclusión política real de las FARC; la construcción 
de una cultura política y ciudadana más incluyente, tolerante, democrática e igualitaria; la búsqueda e identificación de desaparecidos; el fortalecimiento, y blindaje debido, de los movimientos sociales; el robustecimiento de la función crítica y social de la Universidad, entre otros asuntos clave.

Este libro es uno de los tantos aportes que desde CLACSO haremos a la construcción de la paz en Colombia. Sabemos que los gigantescos y complejos desafíos que enfrentaremos interpelarán nuestra imaginación y nuestro compromiso democrático.
CLACSO tiene tantos años como la guerra que comienza a concluir en Colombia. Y CLACSO tendrá tantos años como la paz que finalmente triunfará. Seguiremos trabajando activamente para hacer de las ciencias sociales y de las humanidades un aporte fundamental y necesario a las luchas que harán de esta gran nación, una tierra de libertad, de justicia, de igualdad y de felicidad. ¡Viva la Paz! ¡Viva Colombia!

Eduardo Rueda, Sara Victoria Alvarado y Pablo Gentili 